\title{
Revelaciones de un manuscrito francés sobre las islas Malvinas: Louis-Antoine de Bougainville en los contornos de la América hispana (1767)*
}

Revelations of a French manuscript on the Malouine Islands: Louis-Antoine de Bougainville in the margins of Spanish America (1767)

\section{Carolina Martínez}

\section{(2) OpenEdition}

\section{Journals}

\section{Electronic version}

URL: http://journals.openedition.org/corpusarchivos/1928

DOI: $10.4000 /$ corpusarchivos. 1928

ISSN: 1853-8037

\section{Publisher}

Diego Escolar

\section{Electronic reference}

Carolina Martínez, « Revelaciones de un manuscrito francés sobre las islas Malvinas: Louis-Antoine de Bougainville en los contornos de la América hispana (1767)*», Corpus [En línea], Vol. 7, No 2 | 2017, Publicado el 26 enero 2018, consultado el 19 abril 2019. URL : http://journals.openedition.org/ corpusarchivos/1928; DOI : 10.4000/corpusarchivos.1928

This text was automatically generated on 19 April 2019 


\title{
Revelaciones de un manuscrito francés sobre las islas Malvinas: Louis-Antoine de Bougainville en los contornos de la América hispana $(1767)^{*}$
}

\author{
Revelations of a French manuscript on the Malouine Islands: Louis-Antoine de \\ Bougainville in the margins of Spanish America (1767)
}

\section{Carolina Martínez}

\begin{abstract}
"No es posible que en una región tan vasta no haya algún continente inmenso de tierra sólida capaz de mantener el globo en equilibro..."
\end{abstract}

\section{Charles de Brosses, Histoire des navigations aux terres australes, 1756.}

1 El objetivo del presente artículo es examinar las observaciones sobre las islas Malvinas y el área geográfica circundante realizadas por el navegante francés Louis-Antoine de Bougainville en vísperas de su restitución a la Corona española, hecha por Francia a comienzos de $1767^{1}$. El manuscrito en el que están contenidas dichas observaciones, patrimonio del Archivo General de la Nación de la República Argentina, se presenta como una fuente de interés por sus aportes a tres áreas de estudio diferenciadas. En primer lugar, permite examinar las transformaciones en la competencia ultramarina ocurridas en la segunda mitad del siglo XVIII, en un contexto específico tal como el de los viajes de exploración de tipo científico pero también políticos emprendidos por las distintas potencias ultramarinas a los mares del sur. En la fuente no solo se describen los vientos, las mareas y el clima de las islas sino que se evalúa la utilidad de los recursos disponibles en ellas y su posición geoestratégica respecto del estrecho de Magallanes, sus pobladores 
y las posesiones españolas en América. Tanto el archipiélago como el área magallánicofueguina se presentan en este sentido como parte constitutiva de lo que podría denominarse una geopolítica atlántico-austral en los años previos a las revoluciones de independencia.

2 En segundo lugar, la comparación de las observaciones manuscritas con la descripción de las islas tal como fue presentada en la primera edición del Viaje alrededor del mundo (Bougainville, 1771) refleja las tensiones entre los usos oficiales y públicos del material recabado en las islas. El manuscrito con las observaciones fue, sin duda, un documento de circulación interna y por ello libre de retoques editoriales. En él se revelan las intenciones políticas de la Corona francesa, interesada en establecerse en algún punto estratégico del hemisferio austral, así como en entablar relaciones de intercambio favorables con las poblaciones indígenas de la costa magallánico-fueguina. ${ }^{2}$ En el relato de viaje de Bougainville pueden apreciarse, en cambio, las elecciones editoriales detrás de la publicación, adaptada al gusto del público lector a través de una minuciosa selección del material disponible sobre las islas. La información estratégica para el aprovisionamiento de madera en la zona del estrecho o las recomendaciones respecto de qué debía obsequiarse a los pobladores de la región, por ejemplo, son omitidas en el texto impreso, que pondera el clima y describe los posibles usos de la flora y fauna del archipiélago.

Por último, la particular ubicación de este manuscrito, originalmente dirigido al monarca francés pero actualmente en posesión del Estado argentino (en el marco de su reclamo por la soberanía de las islas), invita a reflexionar sobre las derivas políticas de una experiencia de colonización temprana en el mundo contemporáneo. En este sentido, el análisis del derrotero de la fuente desde su confección en 1767 es tan valioso como el estudio de su contenido, pues contribuye de igual manera a la construcción de una historia del espacio atlántico sur. Es sobre las tres cuestiones hasta aquí mencionadas que el presente trabajo propone indagar.

\section{Restitución de las islas Malvinas a España: la fuente en su contexto de producción}

El primer viaje francés a las islas Malvinas fue conducido entre 1763 y 1764 por LouisAntoine de Bougainville, quien por motivos políticos se vio obligado a levantar la colonia allí fundada en un segundo viaje realizado dos años después. ${ }^{3}$ Su restitución a la Corona española en 1767 se convirtió, sin embargo, en la perfecta excusa para emprender el primer viaje de circunnavegación francés (1766-1769), capitaneado por el propio Bougainville y aprobado por Luis XV poco antes de que desde el puerto de Brest partiera la expedición en la fragata real $\mathrm{La}$ Boudeuse. ${ }^{4}$

5 Con el primer viaje francés alrededor del mundo, Bougainville, quien ya había prestado servicio a la Corona francesa en Canadá durante la Guerra de los Siete Años (1756-1763), volvía a presentarse como un valioso servidor del rey. ${ }^{5}$ Brindó a este último sus agudas observaciones de la situación política en tierras americanas tanto bajo dominio portugués como español, así como una pormenorizada descripción de los territorios meridionales de América y de las islas que fue avistando en su derrotero hacia las Indias Orientales. Todo ello fue publicado en su Viaje alrededor del mundo (1771), versión revisada de su diario de a bordo ${ }^{6}$ que gozó de gran éxito editorial y fue rápidamente traducida por sus competidores ingleses. ${ }^{7}$ Además de incluir una dedicatoria al rey, un discurso preliminar y una serie de 
cartas náuticas, la descripción del viaje se encontraba dividida en dos partes. La primera comprendía el período desde la partida de Francia hasta la salida del estrecho de Magallanes. La segunda, un tanto más extensa, narraba las observaciones hechas por Bougainville desde la entrada al océano Pacífico o mar Occidental hasta el regreso de la expedición a Francia en 1769.

6 Ahora bien, además de las informaciones puestas a disposición del público lector en aquel tipo de publicaciones, existieron documentos de carácter oficial para uso interno del almirantazgo y la Corona. En ellos se informaba sobre la organización del traspaso de las islas a manos españolas, el pago de una compensación a la Compañía de Saint-Malo por parte de España, y el destino de los colonos franceses que por aproximadamente tres años las habían habitado. ${ }^{8}$ Por su singularidad, se destacan de este conjunto los siete folios en recto y verso que constituyen las "Observations générales sur les Iles Malouines" (Observaciones generales sobre las islas Malvinas), firmados por Bougainville el 23 de abril de 1767. Esta fecha indicaría que el manuscrito con las observaciones fue signado por el militar francés después de haber restituido las islas Malvinas a España y a poco de embarcar a los colonos franceses allí asentados. En efecto, la cesión del archipiélago se había producido el 1 de abril de 1767, veintidós días antes de la fecha en la que están datadas las “Observaciones generales...". Señala Bougainville en el capítulo III de su Viaje alrededor del mundo:

7 El 1 de abril entregué nuestro establecimiento a los españoles, que tomaron posesión enarbolando la bandera de España. ... Les leí a los habitantes franceses de esta nueva colonia una carta del Rey por medio de la cual les permitía quedarse bajo el dominio del Rey Católico (Bougainville 2005, p. 93).

8 Los detalles de la devolución se habían acordado con Francisco de Paula Bucarelli, gobernador general de Buenos Aires entre 1766 y 1770, quien envió junto a La Boudeuse dos fragatas españolas al mando de Felipe Ruis Puente, nombrado gobernador de las islas Malvinas, para su toma de posesión. ${ }^{9}$ Debido a los acuerdos establecidos entre los respectivos ministros de los borbones Carlos III de España y Luis XV de Francia, la restitución fue hecha en relativos buenos términos, aspecto que el propio Bougainville resalta en su relato de viaje. ${ }^{10}$ De hecho, la Corona española compensó a la compañía fundada por Bougainville, su tío y su primo por los gastos ocasionados.

9 Tal como fue adelantado al inicio del presente artículo, es probable que la fundación de una colonia francesa en aquel archipiélago haya sido consecuencia directa de la Guerra de los Siete Años, pues la firma del Tratado de París en 1763 había confirmado la victoria de Inglaterra sobre Francia en América. Tras perder todos sus territorios en Canadá, la Corona francesa se propuso hallar un territorio en los mares del sur, acaso la tierra austral incógnita, para compensar la derrota. La exploración marítima del hemisferio sur se convirtió entonces en un objetivo de la Corona, refrendado a su vez por intereses políticos y comerciales tales como los de la francesa Compagnie des Indes, de la que muchos de los propulsores intelectuales de las incursiones australes eran accionistas. ${ }^{11} \mathrm{La}$ expectativa de expansión austral, al menos para Francia, no era en realidad nueva. Desde el siglo XVI cosmógrafos y navegantes habían augurado la conquista de una región austral aún inexplorada al margen de los reclamos de España y Portugal. ${ }^{12}$ Sin embargo, fue recién en el siglo XVIII que la Corona francesa emprendió verdaderas experiencias de navegación a los mares del sur.

10 Es probable que la publicación en 1756 de Histoire des navigations aux terres australes contenant ce que l'on sait des moeurs et des productions des contrées découvertes jusqu'à ce jour ; 
ou il est traité de l'utilité d'y faire de plus amples découvertes, et des moyens d'y former un établissement, de Charles de Brosses, haya potenciado el interés por encontrar un punto de recalada estratégico que permitiera navegar aún más al sur. ${ }^{13}$ Efectivamente, el llamado a encontrar un puerto intermedio entre el mundo conocido y la Tierra Austral realizado por de Brosses en su Histoire des navigations... (1756), ${ }^{14}$ es asociado por Bougainville a la posible utilidad de las islas. Este interés también había sido esbozado por Anson, algunos años antes, cuando en A Voyage Round the World, in the years MDCCXL, I, II, III, IV (1748) se había referido a las bondades de las islas y a su utilidad como punto de recalada antes de atravesar el cabo de Hornos. El navegante inglés, quien no había visto las islas pues se dirigió desde el puerto de San Julián hasta el cabo de las Vírgenes, recomendaba explorarlas con más detenimiento por su posición estratégica:

Las islas Falkland han sido vistas por numerosos navíos franceses e ingleses; Frézier las coloca en su carta de la extremidad de América meridional, denominándolas Islas Nuevas. Woodes Rogers, que bordeó la costa nordeste en 1708, nos dice que se extienden sobre una longitud aproximada de dos grados y ofrecen terrenos ondulados, de aspecto fértil, sembrados de bosques y donde no faltan buenos puertos. Por su distancia del continente y su latitud, esas islas deben gozar de clima templado. Cierto es que son aún demasiado poco conocidas para ser recomendadas desde ahora como lugar de abastecimiento para los navíos que se dirigen al cabo de Hornos, pero si el almirantazgo juzga oportuno hacerlas explorar lo podría con poco gasto... (Walter 1748, pp. 90-91). ${ }^{15}$

Es posible que Bougainville leyera la traducción al francés del viaje de Anson, publicada en París en 1766 bajo el título de Voyage de la Mer du Sud: fait par quelques officiers commandant le vaisseau le Wager: pour servir de suite au voyage de Georges Anson: traduit de l'anglois. ${ }^{16} \mathrm{Al}$ comienzo del capítulo III de su Viaje alrededor del mundo, el capitán francés señala que por su favorable posición el archipiélago "servía como estada para los navíos que se dirigían al Mar del Sur y como escala para el descubrimiento de tierras australes, cosa que captó el interés de los navegantes de todas las naciones" (Bougainville 2005, p. 93). ${ }^{17}$ Haya sido por influencia de De Brosses o Anson, es posible afirmar que el afán de dar con Terra Australis (Mapa $\mathrm{N}^{\circ} 1$ ), cuya existencia se descartaría solamente con las navegaciones de James Cook a fines del siglo XVIII, potenció los viajes de exploración científicos franceses en el transcurso de ese mismo siglo. ${ }^{18}$ En este contexto, tanto en el viaje de Bougainville como en los viajes de La Condamine (1735-1744) y Lapérouse (1785-1788), la figura del explorador se convertió en la del savant ilustrado, encarnada en el viaje de circunnavegación por el naturalista Philibert Commerson y el astrónomo Pierre-Antoine Véron.

13 En relación con lo antedicho, conviene detenerse en la definición de "explorador" dada por Marie-Noëlle Bourguet para el Siglo de las Luces. En términos de la historiadora francesa, en tanto enviado oficial, el explorador tiene a su cargo la misión de descubrir una tierra lejana, pudiéndose encontrar en ocasiones "atrapado en el juego de rivalidades políticas e internacionales” (Bourguet 1995, p. 270). Para Bourguet, la naturaleza combinada de sus funciones no pareciera alterar el objetivo último de este tipo de viaje pues, "al pasar de un objetivo bélico (la evaluación de las fuerzas enemigas) a un programa erudito (completar las cartas marinas y el inventario de los continentes), la naturaleza de su misión adquiere un carácter distinto", la conquista pasa a ser de carácter intelectual y en este sentido, planetaria (Bourguet 1995, p. 271).

Así, Bourguet destaca el interés científico de los exploradores y, aunque no descarta la existencia de un vínculo entre ciencia e imperio, pareciera soslayar la importancia de los 
intereses político-económicos a los que respondieron las misiones científicas en la segunda mitad del siglo XVIII. Una lectura atenta de la fuente demuestra, sin embargo, que los objetivos de viajeros y naturalistas coincidieron muchas veces con los intereses materiales de las distintas coronas europeas en ultramar. Al fundar la colonia en las islas, por ejemplo, tanto Bougainville como su capellán de abordo, Antoine-Joseph Pernety, narran cómo se construye un obelisco y decora una de sus caras con una efigie del rey. Debajo del mismo se entierran unas monedas y una medalla con la que claramente se establece la posesión francesa sobre las mismas. El hecho de que la empresa no ha sido patrocinada económicamente por la Corona pero sí ha contado con su aval político también es significativo en este sentido (Bougainville 2005, p. 97). ${ }^{19}$

Por otra parte, Bougainville refiere constantemente a las navegaciones inglesas por los mares del sur, dando cuenta de la avidez, por parte de Francia, de conocer y seguir los pasos de Inglaterra. El capitán conoce las experiencias inglesas a través de los viajes de Byron (1764-1766), Anson (1740-1741) y Hawkins (1593), a quienes cita en su Viaje alrededor del mundo. ${ }^{20}$

\section{Mapa $N^{\circ} 1$}

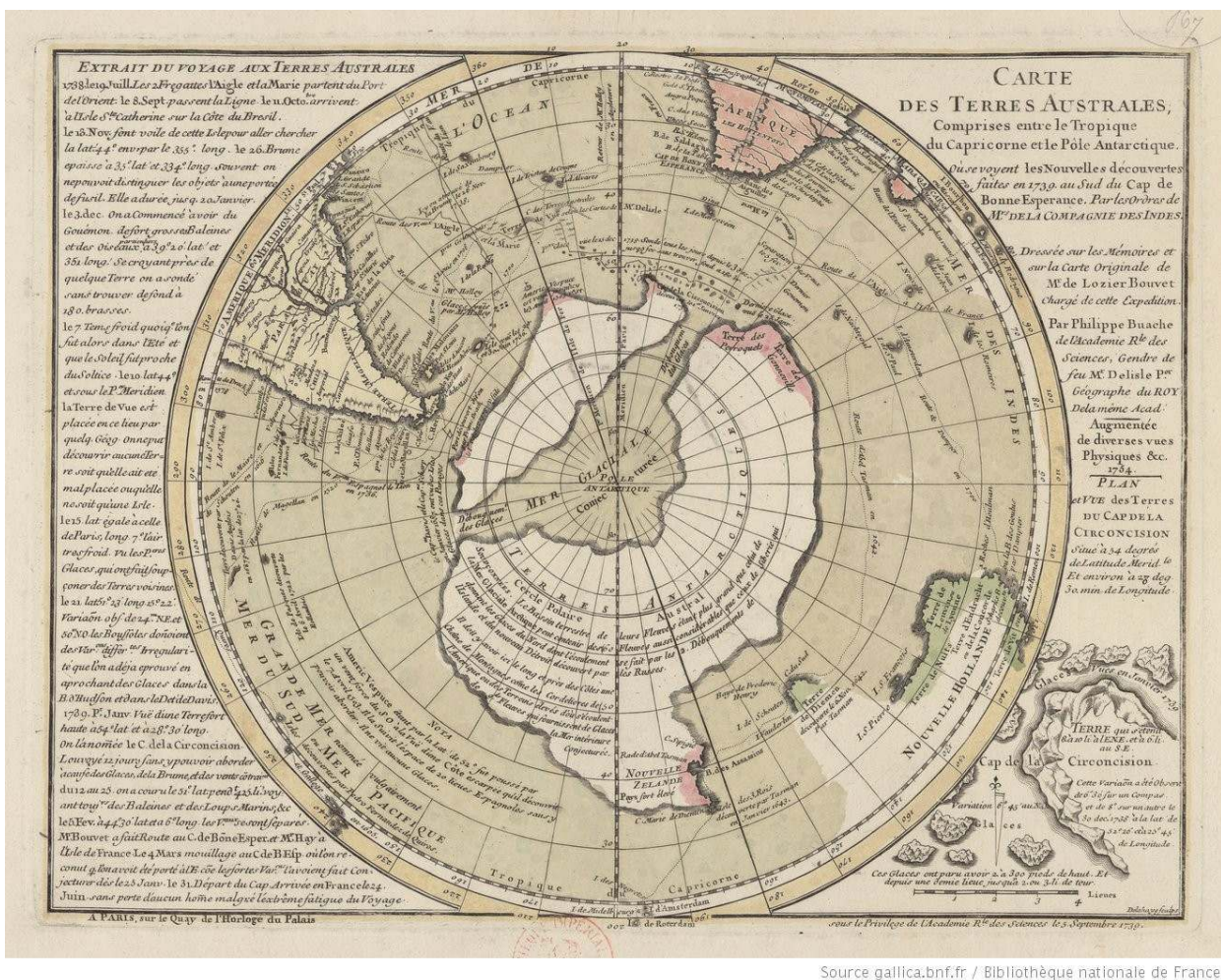

MAPA $N^{\circ}$ 1. BUACHE, PHILIPPE, CARTE DES TERRES AUSTRALES COMPRISES ENTRE LE TROPIQUE DU CAPRICORNE ET LE PÔLE ANTARCTIQUE, OÙ SE VOYENT LES NOUVELles DÉCOUVERTES FAITES EN 1739 AU SUD DU CAP DE BONNE ESPERANCE PAR LES ORDRES DE MRS DE LA COMPAgNIE DES INDES / DRESSÉE SUR LES MÉMOIRES ET SUR LA CARTE ORIgINALE DE MR LE LOZIER BOUVET CHARgÉ DE CETTE EXPEDITION PAR PHILIPPE BUACHE, SUR LE QUAY DE LA MEgISSERIE AU ST ESPRIT PRÈS LE PONT NEUF, SOUS LE PRIVILÈge DE L'ACADÉMIE ROYALE DES SCIENCES, PARÍS, 1739 (FUENTE: BIBLIOTHÈQUE NATIONALE de FRANCE, DÉPARTEMENT DE CARTES ET PLANS, GE D-12838 A). 


\section{Observaciones sobre las islas Malvinas: revelaciones de un escrito de circulación interna}

Una comparación entre la descripción de las islas tal como aparece en las "Observaciones generales..." y la forma en la que estas son descriptas en la primera edición del relato de viaje de Bougainville, revela una serie de diferencias entre el manuscrito firmado tras su devolución y el texto impreso. ${ }^{21}$ En este sentido, si bien se constata que las informaciones sobre las islas provistas en el documento firmado por Bougainville en 1767 son las que utiliza el navegante para redactar el cuarto capítulo de su libro, pueden observarse alteraciones $u$ omisiones de algunos apartados del manuscrito. Es probable que las obliteraciones hayan obedecido a decisiones de criterio editorial, por un lado, pero también a la voluntad de mantener cierta reserva respecto del contenido político del manuscrito. En efecto, más allá de que ambos textos exaltan las bondades de las islas, una lectura atenta de la fuente hace evidentes las omisiones del impreso.

Así, por ejemplo, el capítulo IV del Viaje alrededor del mundo (1771) no hace referencia alguna al beneficio económico que podría sacarse del comercio de pieles (i.e. a partir de la caza de los lobos y leones marinos que habitan las islas) ni a la posición estratégica de las islas frente a un posible continente austral. Tampoco alude al trato con las poblaciones nativas que, si bien no concierne directamente a las islas puesto que estaban inhabitadas, sí es materia de comentario en las "Observaciones generales..." cuando Bougainville refiere a los pobladores del Estrecho. Este, al igual que otros aspectos, se encuentra desarrollado a lo largo de los siete folios que conforman las "Observaciones generales...", divididas en doce partes o secciones bajo los siguientes subtítulos: a) "sobre el clima y los vientos"; b) "sobre las cualidades del aire"; c) "sobre las mareas"; d) "sobre los medios más expeditivos que se hallaron para hospedarse"; e) "sobre los medios que se ofrecen en un futuro para la construcción de viviendas"; f) "sobre los materiales combustibles del territorio de las islas"; g) "sobre las producciones alimenticias del territorio de las islas"; h) "sobre la buena calidad de las pasturas"; i) "sobre los ensayos para hacer cultivos"; j) "sobre las producciones de las cuales la industria puede obtener productos considerables"; k) "sobre los objetos de especulación en relación con la posición de las islas"; y l) "sobre los conocimientos adquiridos en el Estrecho de Magallanes".

El análisis de la fuente revela que muchas de estas secciones desarrollan, con mayor profundidad que en el relato de viaje, los distintos aspectos referidos a las características naturales de las islas, al tiempo que expresan consideraciones de carácter económico o geopolítico ausentes en el texto impreso. Tal es el caso del apartado sobre "las producciones de las cuales la industria puede obtener productos considerables”. En él, Bougainville destaca la pesca de la ballena así como la ya mencionada caza de lobos y leones marinos como potenciales fuentes de riqueza gracias a su aceite y cueros. En el verso del Folio 5, establece: "Hasta el momento se ha obtenido una cantidad de aceite de excelente calidad... y por medio de los curtidores establecidos aquí, se prepararon las pieles en todo tipo de forma, en cueros menos livianos, en marroquíes, en cuero fuerte (... ) etc." (Bougainville 1767, f. 5 v).

19 El manuscrito también enfatiza la ventajosa posición geoestratégica de las islas, aspecto que el texto impreso retoma más moderadamente. De tal forma, en la sección dedicada a "los objetos de especulación en relación con la posición de las islas", Bougainville destaca su proximidad al estrecho de Magallanes y la consecuente posibilidad de obtener en 
aquella región la madera necesaria para la vida en las islas, pues se trata de un combustible del que las mismas carecen. Asimismo, considera que en términos comerciales su ubicación estratégica mejoraría el flujo del comercio por los mares del sur:

(...) cuán útiles serán ellas a los navíos expedidos de Europa y de América, a los cuales ellas pueden servir de excelente escala, tanto por la cantidad, la extensión y la seguridad de sus puertos, cuanto por la restauración y aprovisionamiento que allí encontrarán, y que volverán menos críticas las expediciones en el mar del sur... (Bougainville 1767, f. 5 v.)

$20 \mathrm{Al}$ describir el hallazgo de las islas en el Capítulo III de su Viaje alrededor del mundo, Bougainville señala en cambio: “... por su favorable posición servía como estada para los navíos que se dirigían al Mar del Sur y como escala para el descubrimiento de tierras australes, cosa que captó el interés de los navegantes de todas las naciones" (Bougainville 2005, p. 95). ${ }^{22}$

21 En relación con los indígenas patagónicos, el breve manuscrito hace especial hincapié en el trato que el capitán francés juzga debe darse a las poblaciones de la costa magallánicofueguina. Asentadas en territorios nominalmente bajo jurisdicción española, las sociedades locales son concebidas como entidades diferenciadas cuyos vínculos, de ser reforzados, operarían en beneficio de los franceses en eventuales incursiones por aquellas regiones. En este sentido, si bien Bougainville destaca que "se debe desconfiar mucho de aquella (nación) que está en los alrededores de la Bahía Famine”, ${ }^{23}$ no duda en indicar lo siguiente:

Si se tiene la intención de continuar la alianza entablada por los franceses con los salvajes del Cabo Gregorio, he aquí la lista de obsequios que les fueron hechos de parte de su Majestad Cristianísima, ${ }^{24}$ que ellos recibieron con gran placer, y de aquello que podría agregarse en el futuro (Bougainville 1767, f. 6 v.).

Seguidamente realiza la lista de obsequios otorgados hasta entonces por la cCorona francesa y la lista de obsequios a regalar en un futuro. La referencia a un tiempo futuro pareciera refrendar el hecho de que las observaciones fueron muy probablemente hechas en algún tiempo anterior a la devolución de las islas, cuando Francia aún proyectaba establecerse allí de manera permanente. Entre los objetos ya entregados se mencionan hachas, porras, bonetes de color, hilo y agujas. En la lista de bienes de intercambio futuros se indican telas de colores brillantes, porras en cantidad, pipas y tabaco, sombreros y camisas "muy grandes", pañuelos y espuelas de hierro y cuero entre otros objetos (Bougainville 1767, f. 7 r.). Si bien la mención a las camisas y sombreros de gran tamaño podría estar vinculada al mito de los gigantes patagones, al que Antoine-Joseph Pernety había adscripto en el primer viaje realizado por Bougainville a las islas Malvinas (1763-1766), la evidencia es insuficiente para vincular las sugerencias hechas en las "Observaciones generales..." a la creencia en dicho supuesto. La hipótesis pierde aún más peso si se toma en cuenta que en el apartado precedente, "Sobre los conocimientos adquiridos en el Estrecho de Magallanes", Bougainville afirma que los cascos hechos con pieles de guanacos utilizados por los pobladores de la bahía Famine los hacían de un "tamaño por encima de lo común", cuando en realidad "los más pequeños eran de 5 pies y 8 pulgadas, y los otros llegaban a los 6 pies" (Bougainville 1767, f. 6 r.). Al margen de esto último, es con esta lista de eventuales obsequios que concluyen las observaciones sobre las islas Malvinas firmadas por Bougainville. De tomarse en cuenta su ubicación actual, es probable que jamás hayan llegado a manos del rey de Francia. 
oce deudor de las observaciones de $\mathrm{M}$. de Nerville, quien permaneció en las islas por un período de tres años y, por ello, devino un testigo ocular tanto o más competente que el capitán francés. Al final del tercer capítulo, aclara entonces: "Los detalles acerca de las producciones de estas islas y de los animales que allí se encuentran son materia del próximo capítulo, fruto de las observaciones que le proporcionó a M. de Nerville aquella experiencia de tres años" (Bougainville 2005, pp. 98-99). Michel-François Bougainville de Nerville era primo hermano de Louis-Antoine y es quien coincidentemente firma el manuscrito de las "Observaciones generales..." junto con Bougainville al final de los siete pliegos. ${ }^{27}$ Es probable entonces que el artífice de las observaciones haya sido el propio Nerville, quien produjo un documento certero sobre las islas, avalado luego por el propio 
Bougainville. Una lectura atenta de las secciones que componen el escrito revela que las observaciones ciertamente debieron hacerse en un período prolongado de tiempo y que tal vez fueron escritas en una primera versión antes del regreso de Bougainville a las islas. En el documento se habla de los medios que se ofrecen "en un futuro" para la construcción de viviendas así como de los productos de los cuales la industria podría obtener considerables beneficios, o de la posición estratégica de las islas. En este sentido, tal como se ha anticipado, no pareciera tratarse de un documento escrito en el contexto de la devolución de las islas sino producido en un momento previo, en el que Francia proyectó futuras incursiones en aquella área del globo. Más allá de estas conjeturas, lo cierto es que, se tratara de la pluma de Nerville o del propio Bougainville, la versión presentada al público general resultó una selección del contenido presente en el manuscrito, con inclusiones casi textuales de este último pero depurado a la vez de su contenido más polémico. ${ }^{28}$

En cuanto al trato establecido con los habitantes de la costa magallánico-fueguina, es recién en el capítulo VIII de la primera edición del relato de viaje que se hace alusión a ellos. Al narrar el cruce por el estrecho, son descriptas algunas de las peripecias atravesadas por los marineros de la Étoile (Bougainville 2005, p. 167) que ya habían sido descriptas en las "Observaciones generales..." (Bougainville 1767). La búsqueda de leña en las costas del cabo Gregorio en tiempos del asentamiento francés en las islas, ya había propiciado algunos encuentros con los habitantes de la zona, que en esta parte del relato se describen como "buenas personas" que "parecían muy contentas con nuestro arribo" (Bougainville 2005, p. 168). Es en este capítulo entonces que Bougainville señala algunas de las características y gustos de los pobladores del estrecho, indicados anteriormente en las "Observaciones generales...". Así, por ejemplo, si en los siete folios manuscritos se había destacado la fascinación que ocasionaban a dichos pobladores las telas de colores brillantes, en relato de viaje, Bougainville señala:

31 Les cambiamos algunas bagatelas -que, según ellos, eran preciosas- por pieles de guanaco y vicuña. Por medio de señas, nos pidieron tabaco para fumar y parecía encantarles el color rojo: en cuanto percibían alguna cosa que tuviésemos de este color, se acercaban y pasaban la mano por encima, demostrando un enorme deseo de tomarlo (Bougainville 2005, p. 169).

\section{Derrotero de un manuscrito: nuevos intereses en otros tiempos}

Las "Observaciones generales sobre las Islas Malvinas" de Bougainville se encuentran actualmente en el Archivo General de la Nación, producto de una serie de políticas institucionales que, desde la creación del Archivo General de la Provincia de Buenos Aires en 1821, tuvieron como finalidad "reunir, ordenar y conservar la documentación que la ley le confía, para difundir el conocimiento de las fuentes de la historia Argentina". ${ }^{29}$ Anteriormente, el manuscrito había formado parte del acervo documental perteneciente a la Biblioteca Pública de Buenos Aires, convertida en 1884 en la actual Biblioteca Nacional. Es por ello que el documento figura en el tomo I del catálogo confeccionado por Paul Groussac hacia 1905 para uso interno de dicha institución. Bajo el título completo de Catálogo por orden cronológico de los manuscritos relativos a América existentes en la Biblioteca Nacional de Buenos Aires, el historiador francés, quien fuera director de la misma entre 1885 y 1929, relevó así el fondo bibliográfico allí conservado. ${ }^{30}$ Cuando en 1954 se dictó el 
decreto No. 19.021 de Concentración de Fondos Documentales, la disputa inicial entre la jurisdicción del Archivo General y aquella de la Biblioteca Nacional fue saldada en favor de la primera. En consecuencia, la Biblioteca Nacional se vio en la obligación ceder al Archivo los documentos conservados hasta entonces. Es probable que haya sido en ese entonces que el manuscrito de Bougainville llegara a este último destino.

Mientras Groussac dirigió la biblioteca, publicó Les Iles Malouines (1910), obra en la que relataba la historia de ocupación de las islas para fundamentar la legitimidad del reclamo argentino de soberanía. ${ }^{31}$ Esta edición en francés, impresa en Buenos Aires en 1910, incluye un mapa de las islas y la transcripción de una serie de documentos tanto franceses como españoles e ingleses relativos a la posesión del archipiélago. Pero, extrañamente, no hace referencia alguna a las "Observaciones generales...". Su ausencia es llamativa por el hecho de tratarse de un libro escrito como resultado del minucioso trabajo realizado por Groussac con la documentación existente sobre las islas en la Biblioteca Nacional. A dicho estudio, Groussac agregaba, a su vez, un análisis exhaustivo de los relatos de viaje ingleses y franceses en los mares del Sur. Así lo explica el propio director en una aclaración en pie de página al comienzo de la obra:

Para las personas que lean este trabajo en la impresión aparte, conviene precisar su verdadera naturaleza. Era, en principio, una simple introducción explicativa, análoga a todas aquellas que preceden a los documentos inéditos cuya publicación es asunto habitual de los Anales de la Biblioteca Nacional de Buenos Aires. Cuando debamos, en las páginas siguientes, hacer alusión o una referencia precisa, con indicación de la página y del número de orden, a los "Documentos sobre las Islas Malvinas", se tratará, salvo indicación contraria, de las piezas contenidas en el tomo VI de los Anales. Esa colección, destinada, como lo indica su título, a la publicación con introducciones y notas, de documentos relativos al Río de la Plata, no es oficial más que desde el punto de vista de la subvención que le asigna el gobierno argentino. En lo que concierne a la elección de los materiales, de la que el gobierno jamás tuvo ni ha pedido conocimientos previos, se le asigna plena libertad al director de los Anales. ${ }^{32}$

Los documentos relativos a las Islas Malvinas que Groussac menciona e incluye al final de la obra son, entre otros, la nota firmada por Bougainville concerniente a la cesión de Malvinas y al pago de una compensación, una copia de la "carta que escrive a un amigo el P.e Fr. Sebastian Villaneuva Reli.o Fran.co de las Islas Maluynas en 25. de Abril de 1767", la "Intimación del Comandante español al comandante inglés con la respuesta de este" y la traducción al español de lo que Groussac denomina los "State Papers" (papeles oficiales) ingleses sobre las islas. Es posible que la falta de referencia a las "Observaciones generales...", radicara en el hecho de que las mismas no eran de particular utilidad en la argumentación de Groussac, quien deseaba probar la ilegitimidad de la ocupación inglesa, aunque debe aún profundizarse sobre este aspecto. Por su parte, la síntesis de este texto, destinada a los institutos de enseñanza pública y publicada a pedido del senador Alfredo Palacios en 1936, no contiene el mapa ni los documentos traducidos en la editio princeps.

En cuanto a la relevancia de la fuente aquí traducida en las investigaciones sobre las islas Malvinas realizadas en los últimos años, han aparecido referencias al manuscrito en obras de difusión destinadas a revalorizar la experiencia francesa en las mismas. En 2005, Rafael H. Saiegh reconstruyó la historia de la presencia francesa en el archipiélago con la publicación de Francia en las Islas Malvinas (2005). Allí, son traducidos varios fragmentos de las "Observaciones generales...", documento al que hace referencia en los capítulos XIV y $\mathrm{XV}$ especialmente. En el detallado estudio de las fuentes sobre el asentamiento francés, 
Saiegh señala la importancia del manuscrito, al que dedica el apartado final del capítulo XV que titula: "Cuando la memoria devino historia: las 'Observations Générales...". Es en este capítulo que precisa el contexto de producción de la fuente en cuestión, redactada "durante aquellas semanas de convivencia entre franceses, españoles y criollos" una vez realizada la devolución (Saiegh 2005, p. 243). Fue mientras esperaba el arribo de L'Etoile (que nunca llegaría pues aguardaba a La Boudeuse en Río de Janeiro) que Bougainville permaneció en la isla, hasta que zarpó rumbo a Brasil el 2 de junio de 1767. En su relato de viaje, el propio navegante francés explica al lector:

Mientras esperaba sin resultado el arribo de la Étoile a las islas Malvinas, los meses de marzo y abril seguían transcurriendo, pero la urca no llegaba. Lo cierto era que no podía emprender la derrota del océano Pacífico sólo con mi fragata; su escasa capacidad no le permitía llevar más que seis meses de víveres para su tripulación. Por consiguiente, aguardé a la urca incluso durante todo mayo, pero al ver que sólo tendría víveres para dos meses, el 2 de junio decidimos zarpar de las islas Malvinas rumbo a Río de Janeiro (Bougainville 2005, p. 119).

En los meses previos a su partida, señala Saeigh, Bougainville aprovechó para recorrer "ciertos parajes de la isla, algunos de los cuales (como la ensenada de Yvrogne y la de Beauport) había explorado por primera vez en 1764 con Belcour y Donat" (Saiegh, 2005, p. 243).

Cinco años después de publicada la obra de Saiegh, Gisela Martínez Casado ahondó en la temática con Malvinas, nuestro legado francés (2010). Este escrito incluye una serie de documentos relativos al proyecto francés en las islas, relevados por la autora en los Archivos Nacionales de Francia (Ministère des Colonies), los Archivos del Ministerio de la Marina francesa, la Biblioteca Nacional de Francia y el Archivo General de la Nación (Argentina). La mayoría de los documentos en francés han sido traducidos por Martínez Casado al español, dando al lector la posibilidad de acceder a la edición bilingüe de una porción sustantiva de las fuentes fundamentales para comprender los intereses de Francia en los mares del sur. Entre ellos, se destaca el proyecto para el establecimiento de una colonia en las islas presentado por Bougainville al duque de Choiseul; la "Memoria relativa a las Islas Malvinas y a las Tierras australes" de Louis-Antoine de Bougainville; el acta de toma de posesión de las islas; la "Incorporación de las Islas Malvinas al reino de Francia"; y la "Memoria para anunciar a la corte de España nuestro establecimiento en las Islas Malvinas". Es de interés señalar que dentro del conjunto de documentos relevados por la autora, se incluye una copia facsimilar del primer y último folio de las “Observaciones generales...". Sin embargo, a diferencia de los otros documentos, el manuscrito no ha sido traducido al español ni total ni parcialmente por la autora. Respecto de su contenido, Martínez Casado se limita a señalar que este documento, con fecha del 23 de abril, "contenía detalles geográficos, climáticos y topográficos. Se incluían además, las posibilidades de alojamiento, de exploración de los distintos recursos y referencias a la experiencia francesa en el Estrecho de Magallanes" (Martínez Casado 2010, pp. 87-88).

\section{Reflexiones finales}

El análisis de las "Observaciones generales sobre las Islas Malvinas" aquí presentado debe comprenderse como una primera aproximación a una fuente poco trabajada hasta el momento. Su valor como testimonio de la mirada francesa sobre las islas así como las 
diferencias que presenta el manuscrito in folio respecto del texto editado que representó el Viaje alrededor del mundo permiten explorar las numerosas aristas del proyecto de expansión francés en tierras australes, pero también comprender desde una fuente singular los avatares de la competencia interoceánica europea en el siglo XVIII. En este sentido, su análisis ha procurado complejizar las variables de análisis de lo que podría denominarse una historia del espacio atlántico-austral en el período de la modernidad temprana.

41 Asimismo, la descripción del vínculo que los franceses proponen tener con los habitantes del área magallánico-fueguina en vistas de la eventual consolidación del dominio francés en las islas ${ }^{33}$ revela cómo, en el contexto de exploración atlántica mencionado, la imagen de un otro fue construida en relación con las propias necesidades. En este sentido, al resaltar la conveniente ubicación del archipiélago se lo valora en función de las posibles riquezas de sus habitantes más próximos. Señalan las "Observaciones generales..." sobre las islas:

Se ve cuán ventajoso es para ellas encontrarse actualmente al alcance de una colonia de donde ellas pueden obtener ganado, y tantas otras cosas necesarias, de estar a poca distancia del Estrecho de Magallanes, de donde ellas pueden obtener las maderas para la construcción, las maderas para el fuego, la corteza para la curtiembre, y tal vez por medio del intercambio con las naciones salvajes, muchas riquezas hasta entonces desconocidas (Bougainville 1767, f. 5 v.).

De igual forma, si por un lado el manuscrito establece que "en cuanto a las naciones, se debe desconfiar mucho de aquella que está en los alrededores de la Bahía Famine" (Bougainville 1767, f. 6 v.), es de aquella zona que los franceses necesitan elementos vitales así como establecer posibles alianzas para garantizar su existencia. En este sentido, las "Observaciones generales sobre las Islas Malvinas" no son solamente observaciones. El estudio de la región circundante, en especial de los recursos y pobladores del área magallánico-fueguina, se presenta como un elemento vital del servicio ofrecido por Bougainville al rey de Francia. Así, la detallada descripción de los objetos que serían eventualmente apreciados por las poblaciones fueguinas tanto como las estrategias para formular alianzas frente a un enemigo mayor tal como el imperio colonial español en América ocupan un lugar de importancia dentro de los siete folios manuscritos.

Podría decirse entonces que en las "Observaciones generales..." se reflejan tanto los intereses geopolíticos y los recursos diplomáticos de Francia cuanto el desafío material que implicó el poblamiento de las islas Malvinas, nunca antes habitadas por el hombre. La experiencia francesa en aquel archipiélago fue también la confirmación de que hacia fines del siglo XVIII Ultima Thule podía ser ocupada. Para ello, sin embargo, también fueron vitales las posibles alianzas con las poblaciones del estrecho.

Fuente: “Observations Générales sur les Iles Malouines". Traducción del manuscrito ${ }^{34}$

\section{Folio 1, recto}


El clima de las islas puede ser considerado templado en relación con su latitud meridional a 51 grados y medio. Las estaciones allí no tienen más que matices insensibles, son los vientos los que allí determinan el frío y la sequedad. No se experimentan fuertes calores, o una temperatura marcada, más que en los tiempos de más o menos calma. Si los vientos pasan sobre las tierras del estrecho de Magallanes, participan del frío continental que reina sobre las montañas de ese estrecho y sobre aquellas de Tierra del Fuego, y traen consigo en todas las estaciones o nieves o granizo; jamás, sin embargo, en el transcurso del invierno las nieves fueron considerables; cuando más cayó, no había allí ni dos pies, y a poco que el viento cambió, ella desapareció en poco tiempo. Aquella que cae en las estaciones menos frías, es decir, desde abril u octubre, desaparecía a veces en el día y jamás duró más de dos horas. Los lagos jamás se congelaron más que ese tiempo de forma tal que pudiesen sostener a los hombres, las bahías habitadas y recorridas jamás se congelaron más que contra la tierra por la combinación de aguas dulces que allí precipitan.

\section{Folio 1, verso}

Son los vientos de la parte del sur al S.O. y O.S.O. que traen esa escarcha, y esparcen el frío en el aire; si vienen de la parte del norte y N.O. son lluviosos en cualquier estación; si de la parte del este, brumosos y lluviosos en invierno, claros en el verano; si de la parte del oeste, brumosos y lluviosos en invierno y puros en verano.

63 Los momentos en que los vientos generales son más violentos son durante la época de los equinoccios, los solsticios, las lunas nuevas y llenas, y el momento de crecida de las mareas. Acompañan en verano el movimiento de elevación y de declinación del sol, de forma que tienen su mayor fuerza en el momento en que ese astro pasa por el meridiano, y declinan con él; son una especie de brisas bastante comunes de norte a sur por el oeste en esa estación. Es también del N. al sur por el oeste que los vientos reinan la mayor parte del año.

\section{Sobre las Cualidades del Aire}

64

La reconocida salubridad puede tener por causa los vientos frecuentes que se sienten sobre las islas, a lo cual debe agregarse el estado de incultura en el que han estado las tierras hasta el presente. Por cierto, a excepción de un solo animal cuadrúpedo, mezcla de 
lobo y zorro, y que es muy poco común, no hay sobre las islas más que pájaros de tierra y de mar, casi ningún insecto, ningún reptil, o bestias venenosas, nada en consecuencia capaz de transmitir al aire alguna mala cualidad. Tal vez en el futuro el transporte de una gran cantidad de ganado podrá producir una mutación sensible pero eso sería para mejor, dado que los terrenos, pisados y fertilizados por el ganado, conservarían por más tiempo el calor que el sol les transmitiría, de donde pasaría a la atmósfera y le quitaría a los vientos una gran parte de su sequedad.

\section{Folio 2, recto}

Las pruebas de esta salubridad del aire tienen por fundamento el grado de energía y de salud que han demostrado los colonos hasta el presente la población de la especie humana y de los animales transportados, la ausencia de toda enfermedad epidémica conocida tal como sarampión, viruela, resfriados, pleuresías, fiebres, etc.

\section{Sobre las mareas}

\section{Folio 2, verso}

Puede decirse de las mareas que no son regulares, y que sería difícil confeccionar una tabla exacta; como es costumbre tener en Europa para diferentes puertos. Se ha detectado que el instante de altamar está precedido de tres vicisitudes, o flujos o reflujos consecutivos; llamamos a esas vicisitudes varvodes. Tal vez no son ellas más que el efecto de la prolongación de las bahías en las tierras y de las fricciones irregulares de las aguas, y un puerto abierto inmediatamente al gran mar, como aquel de la Cruzada, marcado sobre el mapa, no esté sujeto a estas irregularidades.

Sobre los medios más expeditivos que se hallaron para albergarse

La necesidad de meterse rápidamente al cubierto en un país desprovisto de madera hizo imaginar un medio muy expeditivo para albergarse. Se sirve para ello de la tierra que cubre al país. Es un compuesto de raíces de hierbas tan entrelazadas que forman un cuerpo lo suficientemente compacto como para construir muros muy sólidos. Todavía no se han levantado muros de más de 6 y 7 pies de alto, primeramente por desconfianza de su solidez, y en segundo lugar por temor a que los vientos tengan demasiado impacto sobre los edificios demasiado elevados. En cuanto a las carpinterías, tres cargamentos de navío trajeron del estrecho suficiente madera para todas las casas actuales, independientemente de la leña para fuego y de una buena cantidad de leña de corte que aún queda.

Respecto a los techos, la isla produce una especie de hierba larga, llamada glajeux, ${ }^{35}$ que equivale a la mejor paja del centeno.

Esas construcciones son de una gran expedición. Fueron construidas en muy poco tiempo algunas considerables tales como el almacén, y el cuerpo de viviendas para los oficiales y familias; podría llegar a decirse incluso que de aquí a algún tiempo no debe construirse más que de esta forma. Debido a que no todos los climas son favorables para otro tipo de construcciones y a pesar de que abundan piedras de varias especies no pueden emprenderse construcciones en piedra sin muchos obreros, a la espera de mano de obra, y sin mucho ganado, a la espera de que se transporten los materiales al sitio. Mientras que 
realizando construcciones de tierra se halla que en los sitios en donde uno se ubique los materiales se encuentran al alcance de la mano.

\section{Folio 3, recto}

\section{Sobre los materiales combustibles}

De los brezos y arbustos que se encuentran a lo largo de los arroyos, y que casi se agotaron en los alrededores de las viviendas al cabo de tres años, se obtiene la turba, materia descubierta y experimentada desde el momento del establecimiento. Ella tiene la ventaja de quemarse sin un olor incómodo y malsano, de dar un calor parejo $\mathrm{y}$, en consecuencia, de conservarse por mucho tiempo encendida, y de transmitirlo tan fácilmente a los cuerpos que se acerquen como podría hacerse con el carbón de madera. Ella es tan común en las islas que, independientemente de los lugares en donde se encuentra en el borde del mar, resultaría difícil hacer una legua sobre el terreno sin encontrarla. En ciertos lugares, quitando la hierba que la cubre, y en otros, por el color negro que manifiesta, de forma tal que los colonos a quienes se considere para ubicarse en el interior de las tierras no estarán jamás alejados de este material esencial, que satisface, prueba hecha, todas las necesidades del hogar, a excepción del calentamiento de los hornos para los cuales hace falta recurrir al brezo y a los arbustos.

77 Para no dejar nada que desear sobre la explotación de esta turba, debe agregarse que se constató que ella no se quema fácilmente estando húmeda y que para sacarle todo el provecho posible haría falta recogerla en el tiempo más seco del año, a saber desde septiembre hasta fines de marzo, y ubicarla en los edificios construidos expresamente para ello de forma tal que el paso de los vientos contribuya todavía más a su perfecta desecación.

\section{Folio 3, verso}

\section{Sobre los productos alimenticios en el territorio de las Islas}

Se cuentan aquí más de 50 especies de animales de caza, en pájaros terrestres y acuáticos. La más abundante de estas especies es conocida por el nombre de avutarda; no es la más fuerte, que es una especie de cisne de cuello negro, pero menos común y menos delicado; 
en cuanto a las avutardas, ellas no abandonan nunca las islas, hay incluso estaciones en donde ellas son más numerosas que de costumbre, esto es en febrero, marzo y abril. Muchas otras especies en cantidad de 50 y más, de las cuales se acaba de hablar, también están de paso, como los sarapicos, las picazas marinas, etc., no se entrará sin embargo en la descripción de los animales que serán fácilmente observados.

Se han descubierto hasta ahora muchas especies de peces de mar, de los cuales una es la gran especie llamada marsopa blanca o topo de mar; es un pescado muy oleoso; y del cual no se nos ofreció de comer. Hasta ahora solo se mató a uno a golpe de fusil. La pesca parece difícil. En cuanto a los otros peces, se cogen comúnmente todo el año dos especies con redes, a saber una especie de mújol, y el pejerrey ${ }^{36}$ en gran abundancia, así como la sardina en el mes de mayo y junio. En cuanto a los peces que se pescan a la línea, y que existen en gran cantidad, y anónimos, la pesca se hace solo cuando hay barcos en la rada.

Todos esos animales de caza y peces pueden pasar por delicados y no hay ninguno de mal sabor.

81 Se encuentra incluso en invierno bajo los terrenos inestables, a lo largo de los arroyos, una gran cantidad de peces de mar de la especie llamada mújol, que parece elegir este refugio contra la persecución de los lobos marinos, que son grandes destructores de pescados. La forma de atraparlos en sus nichos es conocida por los franceses que permanecen aquí.

\section{Folio 4, recto}

Las lenguas, vísceras y patas de los lobos marinos, pueden ser puestas en el rango de los alimentos. No tienen ningún mal gusto. La lengua es incluso un alimento delicado. El aceite de los jóvenes lobos puede suplir en la cocina en el caso de falte el de oliva.

Después de esos alimentos vienen las plantas en número de tres. El apio o perejil de macedonia; su mejor estación es en invierno, es abundante y refrescante, a diferencia de la propiedad natural de esta planta cultivada en Europa. La acedera, de una forma y de una especie particular del país. La estación es la primavera.

La planta de la cerveza, que se encuentra en abundancia todo el año y cuya desecación con la melaza, hecha de granos y mazamorra, compone un licor que puede servir de bebida.

Estas últimas plantas comportan reconocidas propiedades incluso por fuera, pues la sola desecación de la planta de la cerveza sirvió para dar muy eficaces baños a aquellos de la tripulación que vinieron aquí atacados de escorbuto.

\section{Sobre la buena calidad de los pastizales}

87 Uno de los mejores partidos que puede sacársele a estas islas resulta de la bondad de los pastizales. Los productos de una muy pequeña cantidad de ganado, tal como las bestias con cuernos, ovejas, y cerdos transportados aquí, fueron de calidad superior y la carne de estos animales de un gusto tan bueno como en los mejores climas de Europa. Puede percibirse que será fácil obtener de una gran cantidad de tales animales las mejores mantecas, carnes saladas, pancetas y otras provisiones, y jde qué recurso para los colonos, y para las colonias vecinas será el resultado de esta parte de la industria y del comercio! sobre todo porque nadie estará a cargo de ella en absoluto, todos esos animales pudiendo 
errar en el campo, en todas las estaciones, lo que sirve de prueba convincente en lo que concierne a la temperatura y a la salubridad del clima. En cuanto a los cerdos se tomó el recaudo de transportarlos sobre las islas, esperando que se hallara allí...

\section{Folio 4, verso} la hierba ordinaria, que sola no los alimenta. Esas adormideras marinas son tan favorables a la alimentación del ganado que siempre las prefirió cada vez que pudo elegir.

\section{Sobre los intentos de hacer cultivos}

do que la tierra no ha podido ser jamás abierta en grande y que hasta el presente el arado no ha tenido ganado, ha sido necesario contentarse con la azada y con la pala, y cultivar los granos al reparo de los muros de los jardines, solamente para ponerlos al cubierto de los animales errantes de los alrededores. Recién al segundo año de haber abierto las tierras, la cebada, la avena e incluso una pequeña cantidad de trigo llegaron a una madurez deseada. Las espigas fueron enviadas a Francia. Se espera tener aún más éxito en el tercer año, pero debido a que el invierno fue más rudo que los precedentes y que la siembra no pudo hacerse desde el mes de abril, hizo falta renovar todo en el mes de septiembre, cuando la estación estaba demasiado avanzada para el trigo. Se tienen a la vista, sin embargo, las espigas de cebada y de avena acercándose a la perfecta madurez.

Debe agregarse que independientemente de que la tierra sea todavía nueva, jamás se recurrió al estiércol para enriquecerla debido a la facilidad de transportar hasta allí las plantas marinas que serán una de las causas más seguras de su mejoramiento, y que no se podría haber elegido terreno más protegido, estando obligados a tener todo bajo los ojos y al alcance de las viviendas.

91 No hay duda de que se encuentran sobre la isla una infinidad de lugares donde los vientos tienen menos impulso y donde se tendría más éxito. Por otra parte, la mayoría de las semillas venidas de Europa se activaron durante su travesía. En el futuro, hará falta que sean enviadas en sus espigas e incluso prestar atención a que sean de lugares análogos al clima, ya que es natural pensar que los granos tomados de un país cálido no crecerán en la latitud de las islas tan bien como aquellos recolectados bajo la misma latitud.

\section{Folio 5, recto}

En cuanto a las semillas de las hortalizas, venidas de Francia, y la mayor parte de [ilegible], ellas han crecido muy bien. Las raíces en general prenden bien aquí y el resto depende en mayor o menor grado de la habilidad de los cultivadores.

Los árboles de bosque y los frutales, también enviados desde Francia, se naturalizaron sin esfuerzo, no murió ninguno de aquellos que fueron trasplantados.

En cuanto al trasplante de aquellos del estrecho de Magallanes, se salvaron solo aquellos que eran de tamaño pequeño y habían sido puestos con cuidado en cajas junto con su tierra natal. Este asunto merece la mayor atención. Es probable que se puedan transportar en cantidad suficiente para algún día formar un refugio contra el viento y al mismo tiempo embellecer las islas. La creación de bosques y forestas ha sido siempre, en todos los lugares del mundo, el resultado de la paciencia y del tiempo. 


\section{Sobre las producciones del país de las cuales la industria puede obtener productos} considerables

El primer artículo es la pesca de la ballena. Está comprobado que se encuentran en abundancia alrededor de las islas. Las osamentas que se hallan sobre los bordes del mar prueban que a veces se encallan.

El segundo consiste en lobos y leones marinos. Son muy numerosos en todos los lugares conocidos de las islas, se encuentran donde hay adormideras marinas y a lo largo de las costas cubiertas de esta misma hierba. La pesca que hasta el presente ha sido hecha a tiro, o en barcos en las bahías, no es practicable a lo largo de las costas, en su mayoría rocosas y cuya aproximación es peligrosa a causa de la rompiente. Para sacar todo el provecho posible de esos animales debería matárselos en tierra y transportar a los puertos más próximos los productos que de allí resultaran; a saber, los aceites y las pieles, lo cual sería fácil de realizar con animales de tiro y vehículos.

\section{Folio 5, verso}

Hasta el momento se ha obtenido una cantidad de aceite de excelente calidad en proporción a las expediciones que fueron hechas para la pesca, y por medio de los curtidores establecidos aquí se prepararon las pieles en todo tipo de forma, en cueros menos livianos, en marroquíes, en cuero fuerte, en cuero para [ilegible] y arneses, etc. tanto con la casca venida de Francia como con aquella que se puede hacer con las cortezas de las maderas del estrecho de Magallanes, intento que fue seguido con atención.

En todo, las pieles de los leones son preferibles por la calidad a aquellas de los lobos, pero los leones dan muy poco aceite, mientras que los lobos, que tienen pieles de menor calidad, producen aceite en gran abundancia.

99 Esos animales son muy fáciles de matar, a los medianos golpeándolos sobre la nariz con bastones o garrotes, y a los más grandes, que sobrepasan los 20 pies de largo, de un golpe de fusil que debe encajarse entre los dos ojos.

\section{Sobre los objetos de especulación en relación con la posición de las islas}

Se ve cuán ventajoso es para ellas encontrarse actualmente cerca de una colonia de donde ellas pueden obtener ganado y tantas otras cosas necesarias; de estar a poca distancia del estrecho de Magallanes, de donde ellas pueden obtener las maderas para la construcción, la leña para el fuego, la corteza para la curtiembre y, tal vez por medio del intercambio con las naciones salvajes, muchas riquezas hasta ahora desconocidas. ¡Cuán útiles serán ellas a los navíos que zarpen de Europa y de América! A los cuales ellas pueden servir de excelente escala, tanto por la cantidad, la extensión y la seguridad de sus puertos, cuanto por la restauración y aprovisionamiento que allí encontrarán, y que volverán menos críticas las expediciones en el mar del sur. Podría formarse incluso una rama de comercio, de exportación de la población de ganado transportado, por la facilidad de hacer allí salazón de todas las especies, dado que el clima allí es propicio y que las mantecas y las carnes allí son de excelente calidad. 


\section{Folio 6, recto}

\section{Sobre los conocimientos adquiridos en el estrecho de Magallanes}

\section{Folio 6, verso} peligrosamente herido.

En 1765, los franceses, habiendo fondeado en la bahía Bougainville cerca de la bahía Famine, entablaron alianzas con una nación de salvajes de esos cantones, quienes son de tamaño mediocre y bastante miserable. Se les hicieron obsequios en nombre de su majestad y se les dio una bandera blanca. No se encontraron otras curiosidades entre ellos más que arcos y flechas muy débiles y algunos collares de conchas que sirven para adornar a sus mujeres. Sucedió en los meses de febrero y marzo, durante los cuales hizo mucho más calor del que se esperaba.

En 1766 dos navíos franceses recién cruzaron el estrecho el 24 de abril. Sufrieron el frío durante su travesía e hicieron leña en la bahía de Famine. La Étoile, que fue la primera en zarpar para regresar aquí, se detuvo en el cabo Gregorio, como consecuencia de un encuentro que se dio en ese sitio con una nación salvaje que no dejó de hacer las señales de reconocimiento convenidas. Estableció la alianza e hizo obsequios en nombre de su majestad a los salvajes, que recibieron la bandera blanca con grandes señales de júbilo. ${ }^{38}$ Eran 800 y aún más, hombres, mujeres y niños, todos a caballo. Los jefes bien equipados y bien armados, sea con sables sea o con puñales. Todos tenían pieles de guanaco para cubrirse, botines y bonetes en forma de cascos, lo cual contribuía a su tamaño por encima de lo común. Los más pequeños eran de 5 pies y 8 pulgadas, y los otros llegaban a los 6 pies y más, lo cual daba a ver una bella tropa. Sus caballos son bellos y de gran velocidad. Nos los obsequiaron pero fue imposible embarcarlos. Nos dieron también algunas pieles de guanaco y las pelotas que utilizan para enlazar los caballos y otros animales. ${ }^{39}$

Se observan sobre las planicies a lo largo de la costa numerosas tropillas de guanacos.

La Aigle, por su parte, habiéndose retrasado por su cargamento en la bahía Famine, tuvo un desafortunado incidente con los salvajes de los alrededores. El incidente sucedió entre nuestros carpinteros, que se vieron obligados a permanecer en tierra una noche a causa del mal tiempo, y los salvajes. Estos últimos, al comienzo de la noche se presentaron en la puerta de la cabaña en cantidad de 20 y más. Nuestros obreros no eran más que seis y fueron lo suficientemente afortunados como para tomar a tiempo sus hachas, con las cuales los hicieron huir, después de haber matado a dos. Uno de los nuestros fue

Sucede que la época para ir al estrecho a buscar la madera será fijada desde octubre hasta fines de marzo, y no más tarde. En verdad, las maderas tendrán todavía savia pero se arriesga demasiado esperando que ya no tengan savia, al exponerse desde los meses de abril, mayo y junio, a los rigurosos fríos del estrecho, y traer a la tripulación en parte enferma, como lo hemos experimentado. Por otra parte, siendo las noches muy cortas, la navegación no es tan expeditiva ni la carga tan rápida.

Sin embargo, con las debidas precauciones, se puede hacer allí invernar cada tanto un filibote con carpinteros que cortarán cuando sea la época las maderas para las carpinterías y construcciones. 
107 En cuanto a las naciones, se debe desconfiar mucho de aquella que está en los alrededores de la bahía Famine.

Si se tiene la intención de continuar la alianza entablada por los franceses con los salvajes del cabo Gregorio, he aquí la lista de obsequios que les fueron hechos de parte de su Majestad cristianísima, y que ellos recibieron con gran placer, y de aquello que podría agregarse en el futuro.

Obsequios Dados.

Hachas

111 Porras

Bonetes de color, los más brillantes son los mejor recibidos

Cuchillos de leñador y [ilegible]

114 Hilo

115 Agujas

\section{Folio 7, recto}

\section{[ilegible]}

Bermellón

Telas azules, rojas y violetas

Cinturones salvajes. Algunas pipas y muy poco tabaco

Presentes para obsequiar en un futuro en suplemento a aquellos de más arriba.

Cintas, todas hechas de telas de colores brillantes

y muy amplias

Porras en cantidad

Navajas

Pipas y tabaco en cantidad, tanto para fumar como para masticar

Sombreros muy grandes

Pañuelos

Camisas muy amplias

Utensilios de cuero, e incluso de cuero bruto, al

que parecieran hacer gran caso.

Espuelas de hierro o cuero

Estribos [ilegible]

Bridas y frenos [ilegible]

Hebillas de cuero para la cuadrilla de sus caballos

Cascabeles de cuero de los cuales tienen algunos

Perlas de vidrio ${ }^{40} \mathrm{o}$ grandes perlas falsas

Silbatos de cuero, que les causan mucha curiosidad

Hecho en las islas Malvinas el 23 de abril 1767

De Bougainville 
[Fin de la traducción]

\section{BIBLIOGRAPHY}

Anson, G. (1751). Voyage autour du Monde fait dans les années 1740-41-42-43-44, par George Anson, presentement Lord Anson, Commandant en Chef d'une Escuadre envoyée par Sa Majesté Britannique dans la Mer du Sud. Amsterdam y Leipzig: Arkstee \& Merkus.

Anson, G. (1766). Voyage de la Mer du Sud, fait par quelques officiers commandant le vaisseau le Wager, pour servir de suite au voyage de Georges Anson: traduit de l'anglois. París: Chez les Freres Duplain.

Bernal, R. (2012). El Gran Océano. México: Fondo de Cultura Económica.

Berthelin, M. (1762). Abrégé du dictionnaire universel françois et latin, vulgairement appellé dictionnaire de Trévoux. Contenant la signification, la définition et l'explication de tous les termes de Sciences et Arts, de Théologie, de Jurisprudence, de Belles-Lettres, d'Histoire, de Géographie, de Chronologie, etc. Tomo 3. París: Les Libraires Associés.

Bougainville, L.-A. (1767). Observations générales sur les Iles Malouines, Manuscrito. Archivo General de la Nación, Colección Biblioteca Nacional, Legajo 189, documento no. 1825.

Bougainville, L.-A. (2005 [1771]). Viaje alrededor del mundo a bordo de la fragata real la Boudeuse y la urca Étoile, en 1766, 1767, 1768 y 1769. Buenos Aires: Eudeba/Colección reservada del Museo del Fin del Mundo.

Bourguet, M.-N. (1995). El explorador. En M. Vovelle (Comp.), El hombre de la Ilustración (pp. 265-319). Madrid: Alianza Editorial.

Byron, J. (1767). Voyage autour du monde, fait en 1764 \& 1765, Sur le vaisseau de Guerre Anglois Le Dauphin, commandé par le chef de cadre Byron, dans lequel on trouve une description exacte du Detroit de Magellan, et des géans appellés Patagons, ainsi que de sept isles nouvellement découvertes dans la Mer du Sud. Traduit de l'anglois par M. $\mathrm{R}^{* * *}$. París: Chez Molini.

De Brosses, C. (1756). Histoire des navigations aux terres australes contenant ce que l'on sait des moeurs et des productions des contrées découvertes jusqu'à ce jour; ou il est traité de l'utilité d'y faire de plus amples découvertes, et des moyens d'y former un établissement. París: Chez Durand. Groussac, P. (1905). Catálogo de Manuscritos de la Biblioteca Nacional por orden cronológico. 3 Tomos. Buenos Aires: La Biblioteca.

Groussac, P. (1910). Les Îles Malouines. Nouvel exposé d'un vieux litige. Avec une carte de l'archipel. Extrait des Anales de la Biblioteca Nacional de Buenos Aires. Buenos Aires: Imprimerie Coni frères.

Groussac, P. (1936). Las Islas Malvinas: compendio de la obra de Paul Groussac, para los institutos de enseñanza de la Nación. Buenos Aires: Comisión Protectora de Bibliotecas Populares.

Hawkins, R. (1663). The observations of Sir Richard Hawkins Knight, in his voyage into the South Sea. Anno 1593. Londres: John Iaggard. 
Martínez, C. (2011). Definición, apropiación y construcción del espacio en la tierra austral incógnita. Avances del CESOR, VIII( 8), 91-110.

Martínez Casado, G. (2010). Malvinas, nuestro legado francés. Buenos Aires: Argenta Sarlep.

Paredes, R. C. (2011). Guerra en los libros. La competencia colonial entre Gran Bretaña y Francia en los libros del Museo Etnográfico de Buenos Aires (1690-1800). Avances del CESOR, VIII( 8), 129-154.

Pernety, A.-J. (1769). Journal historique d'un voyage fait aux Iles Malouines en 1763 \& 1764, pour les reconnoître, \& y former un établissement; de deux voyages au Détroit de Magellan, avec une Rélation sur les Patagons, par Dom Pernety, Abbé de l'Abbaye de Burgel, Tomo II. Berlín: Etienne de Bourdeaux.

Pernety, A.-J. (2012 [1770]). Historia de un viaje a las Islas Malvinas. Buenos Aires: Eudeba/ Colección Reservada del Museo del Fin del Mundo.

Saiegh, R. (2005). Francia en las Islas Malvinas. Buenos Aires: Emecé.

Walter, R. (Comp.). (1748). A Voyage Round the World in the Years MDCCXL, I, II, III, IV, by George Anson, Esq. Commander in Chief of a Squadron of His Majesty's Ships, sent upon an Expedition to the South-Seas, complied From Papers and other Materials of the Right Honourable George Lord Anson, and published under his Direction. Londres: John and Paul Knapton.

\section{NOTES}

1. * Una versión preliminar de este artículo fue presentada en las XVI Jornadas Interescuelas/ Departamentos de Historia, realizadas en la ciudad de Mar del Plata en agosto de 2017. Agradezco al Prof. Fabián R. Vega su referencia a la fuente aquí trabajada, así como la atenta colaboración del personal del Archivo General de la Nación.

Se trata de "Obsérvations générales sur les Iles Malouines" ("Observaciones generales sobre las islas Malvinas"), Manuscrito, AGN - Colección Biblioteca Nacional - Legajo 189, documento número 1825. La fuente completa ha sido traducida por primera vez al castellano en el presente artículo. 2. Se trabajará aquí con la traducción de la primera edición del Viaje alrededor del mundo (1771) de Louis-Antoine de Bougainville realizada por EUDEBA en 2005, en el marco de la Colección reservada de la biblioteca del Museo del Fin del Mundo. El contraste entre el manuscrito y el relato editado es particularmente fuerte si se toma en cuenta que la segunda mitad del siglo XVIII fue un período de verdadero auge de los relatos de viaje. En términos de Marie-Noëlle Bourguet, “... con 3.450 títulos franceses y extranjeros -es decir, más del doble que en el siglo anterior-, la literatura de viaje, hasta entonces una parte menor de la producción libresca, se convierte en el siglo XVIII en un género conquistador. En los cuarenta últimos años del siglo, cuando están en boga los viajes al norte y al sur, la diligencia con que los exploradores se apresuran a publicar sus relatos da una idea de la pasión del público hacia estas regiones lejanas" (Bourguet 1995, p. 306).

3. Así inicia Bougainville su relato de viaje: "En el mes de febrero de 1764, Francia comenzó a establecerse en las Islas Malvinas. Sin embargo, cuando España reivindicó estas islas por tratarse de un territorio dependiente de sus grandes extensiones en América meridional, el rey reconoció ese derecho y recibí la orden de entregar nuestro establecimiento a los españoles y luego dirigirme a las Indias orientales, atravesando el Mar del Sur por entre los trópicos" (Bougainville 2005 , p. 69). Sobre el contexto político en el que Bougainville realiza su segundo viaje a las islas Malvinas véase también Bourguet (1995, p. 282) y Bernal (2012, p. 324). Los franceses fueron los primeros en ocupar las islas. Sin embargo, su primer avistamiento se produjo durante la 
expedición del holandés Seebald de Weert en 1600. En 1616 su existencia fue confirmada por Jakob LeMaire, quien las reconoció como las islas Sebaldinas.

4. Bougainville realiza el primer viaje de circunnavegación francés a bordo de La Boudeuse. Este navío sería acompañado por la urca Étoile, con la que Bougainville debía encontrarse en las islas Malvinas. Debido a una serie de averías en esta última embarcación, el capitán francés recién pudo contactarse con ella en Río de Janeiro, tras regresar de las islas Malvinas con las familias de colonos que allí se habían establecido y que, en el marco de su restitución, debieron abandonarlas.

5. La derrota de Francia frente a Inglaterra, la pérdida de los territorios franceses en Canadá y la consecuente firma del Tratado de París en 1763 constituyeron grandes pérdidas para la monarquía francesa. Es probable que Bougainville se lanzara a las islas Malvinas como consecuencia de estos sucesos políticos.

6. La redacción de un diario de a bordo fue obligatoria para los oficiales de la Marina francesa a partir de las ordenanzas de 1689 y 1765 (Bourguet 1995, p. 294).

7. Al respecto, véase el trabajo de Rogelio C. Paredes (2011, pp. 129-154). Sobre las múltiples ediciones del relato de viaje de Bougainville, debe señalarse que entre la primera y la segunda edición en francés, realizadas en 1771 y 1772 respectivamente, la obra sufrió ciertas modificaciones cuando no la supresión total de algunos capítulos.

8. Entre estos documentos cabe mencionar las "Notas dadas por M. de Bougainville, relativas a la cesión de las Islas Malvinas", copia de la copia existente en la Sección de Manuscritos de la Biblioteca Nacional de Río de Janeiro y perteneciente a la Colección Angelis (No. 1217 del catálogo espacial de la referida colección), otorgada al gobierno de la República Argentina el 31 de marzo de 1902 (Legajo 5102). Este documento pertenece a la colección "Biblioteca Nacional" del Archivo General de la Nación. En la misma colección también se encuentra una copia de "Instrumento que otorgó M. Luis de Bougainville a la entrega de las Islas Malvinas" (Legajo 5413), relativo al pago de una indemnización por la ocupación y usufructo de las islas. La referencia a este documento no es anodina pues en una de las notas al pie del capítulo III de su relato de viaje, Bougainville hace referencia al pago de una indemnización tal como es mencionado en el documento citado. El francés destaca la generosidad del rey de España al señalar: "Luego de que Francia reconoció el derecho de Su Majestad Católica sobre las islas Malvinas, el Rey de España por un principio de derecho público conocido por todo el mundo, no debía ningún reembolso de esos gastos. No obstante, como él tomaba los navíos, bateles, mercancías, armas junto con las provisiones de guerra y de boca que componían nuestro asentamiento, este monarca, tan justo como generoso, ha exigido que se nos reembolsaran nuestros anticipos. La suma susodicha fue entregada por sus tesoreros, una parte en París y el resto en Buenos Aires" (Bougainville 2005, p. 93).

9. Señala Bougainville en su relato de viaje: "Las dos fragatas españolas destinadas a tomar posesión de las islas Malvinas estaban en esa rada desde hacía un mes. Su comandante, Don Felipe Ruis Puente, capitán de navío, había sido nombrado gobernador. Regresamos juntos a Buenos Aires a fin de concertar con el gobernador general las medidas necesarias para la cesión del establecimiento que debía entregar a los españoles" (Bougainville 2005, p. 77). En una cédula real de 1766, Carlos III había creado la gobernación de las islas Malvinas, que dependía del gobernador de Buenos Aires. Tras tomar posesión de las islas, Felipe Ruis Puente fue su primer gobernador.

10. Primaba en este acuerdo el miedo a una ocupación inglesa, insinuada por la fundación del Puerto Egmont hecha por John Byron en 1766. Sobre las circunstancias políticas en las que se gestó el segundo viaje de Bougainville a las islas, véase el estudio introductorio al Viaje alrededor del mundo realizado por Andrés G. Freijomil (Bougainville 2005, p. 13-14).

11. Debido al impacto de su Histoire des navigations aux terres australes (1756), la figura de Charles de Brosses fue sin duda una de las más destacadas.

12. De todos ellos se destaca Les Trois Mondes (1582), de Lancelot Voisin de La Popelinière. 
13. El Museo Etnográfico "Juan B. Ambrosetti" de la Ciudad de Buenos Aires conserva una copia de su primera edición.

14. Al respecto, señala De Brosses: “Depuis peu le capitaine Lozier, envoyé par notre compagnie des Indes, pour découvrir quelque port dans les Terres australes, navigeant vers l'Est, entre l'Amérique et l'Afrique, a trouvé pendant une route de 48 degrés des signes continuels de terres voisines, et enfin vers le 52 degré un cap où les glaces l'empêchèrent d'aborder. L'utilité de trouver un port, quoique grande, seroit cependant une des moindres qui résulteroit d'une découverte à laquelle on a trop tôt renoncé, sans y avoir employé les plus justes mesures possibles" (De Brosses, 1756, pp. 2-3). [Hace poco, el capitán Lozier, enviado por nuestra compañía de Indias para descubrir algún puerto en las Tierras australes, navegando hacia el Este, entre América y África, encontró durante una ruta a 48 grados signos continuos de tierras vecinas, y finalmente hacia el grado 52 un cabo cuyos hielos le impidieron abordar. La utilidad de encontrar un puerto, aunque grande, sería sin embargo lo mínimo que podría resultar de un descubrimiento al que se renunció demasiado pronto sin haber empleado los medios más justos posibles.] La traducción es de la autora.

15. Puede accederse al texto completo en la siguiente dirección web:

https://archive.org/stream/voyageroundworld00walt\#page/90/mode/2up/search/Falkland

16. Un ejemplar se encuentra disponible en la Biblioteca Central "Augusto Cortazar" de la Facultad de Filosofía y Letras de la Universidad de Buenos Aires.

17. La observación también es hecha por Antoine-Joseph Pernety, capellán de a bordo del primer viaje de Bougainville a las islas Malvinas (1764-1764). En el discurso preliminar a la Historia de un viaje a las Islas Malvinas (1770) Pernety refiere directamente a De Brosses (Pernety 2012, p. 44).

18. Sobre la importancia de la Tierra Austral para Francia, Marie-Noëlle Bourguet ha señalado: "el debate sobre el continente austral se reinició a mediados del siglo XVIII por obra de los filósofos Buffon y Maupertuis y, sobre todo, del presidente De Brosses. Su monumental Histoire des navigations aux terres australes, publicada en 1756, es una invitación a reanudar exploraciones sistemáticas financiadas por los príncipes europeos: 'No es posible que en una región tan vasta no haya algún continente inmenso de tierra sólida capaz de mantener el globo en equilibro en su rotación y servir de contrapeso a la masa asiática septentrional”" (Bourguet 1995, p. 281).

19. En el caso de Pernety, esto se describe en la página 232 de la edición de Eudeba-Biblioteca del Museo del Fin del Mundo (Pernety 2012, p. 232).

20. Ejemplares de estos relatos de viaje se conservan actualmente en el Museo Etnográfico "Juan B. Ambrosetti" de la Ciudad de Buenos Aires.

21. Las islas son descriptas en el capítulo IV, titulado "Detalles sobre la historia natural de las Islas Malvinas", de la primera edición del Viaje alrededor del mundo (1771). Es de hacer notar que este capítulo fue eliminado en su totalidad de la segunda edición del relato de viaje.

22. La posición estratégica de las islas también había sido resaltada en el discurso preliminar a la Historia de un viaje a las Islas Malvinas de Antoine-Joseph Pernety (2012, pp. 31-38).

23. Bougainville se refiere aquí a Port Famine (Puerto del Hambre), el puerto y zona ubicada en la ribera norte del estrecho de Magallanes nombrada así por Thomas Cavendish en 1587.

24. Este era el apelativo utilizado para designar exclusivamente al rey de Francia. Así como Su Majestad Católica lo era para el rey de España. La referencia directa al rey de Francia es un claro indicio de quien fuera el destinatario original de las "Observaciones generales...", hayan llegado o no a manos de Luis XV.

25. Al respecto, expresa: “¡Los elementos resultaban tan desalentadores que parecían estar anunciando el rechazo que la naturaleza perpetraría contra los esfuerzos de la especie humana por sobrevivir en lugares tan salvajes como éstos!" (Bougainville 2005, p. 101).

26. Al final del capítulo III, Bougainville detalla la situación de los ingleses en las islas: “...el comodoro Byron había llegado en el mes de enero de 1761 a explorar las islas Malvinas. Atracó al oeste de nuestro asentamiento, en un puerto que nosotros ya habíamos denominado puerto de la 
Cruzada, tomando posesión de las islas para la corona de Inglaterra y sin dejar allí ningún habitante. Recién en 1776 los ingleses enviaron una colonia para que se estableciera en el puerto de la Cruzada, al cual llamaron puerto Egmont" (Bougainville 2005, p. 99).

27. Bougainville, Nerville y d'Arboulin, tío de Bougainville, son quienes financian la empresa de colonización en las islas. En 1763, había partido desde el puerto de Saint-Malo la embarcación Aigle con Bougainville y Nerville en ella. Este último permaneció en la colonia fundada en las islas hasta el regreso de Bougainville a las mismas en 1766.

28. En el caso de las mareas, por ejemplo, el manuscrito establece: "Puede decirse de las mareas que no son regulares y que sería difícil confeccionar una tabla exacta; como es costumbre tener en Europa para diferentes puertos. Se ha detectado que el instante de altamar está precedido de tres vicisitudes, o flujos o reflujos consecutivos; llamamos a esas vicisitudes varvodes, tal vez no son ellas más que el efecto de la prolongación de las bahías, en las tierras, y de las fricciones irregulares de las aguas..." (Bougainville 1767, f. 2 r.). La misma descripción aparece textualmente al comienzo del capítulo IV del Viaje alrededor del mundo: "Las mareas, sujetas a todos los movimientos del mar circundante, nunca se han elevado en lapsos precisos que fuese posible calcular. Sólo hemos notado que tenían tres variaciones establecidas antes del instante de su pleamar. Los marinos llaman a estas variaciones varvodes..." (Bougainville 2005, p. 103).

29. Extracto del artículo No. 1 de la Ley 15.930 de 1961, en la que se fijaron las responsabilidades y funciones del Archivo General de la Nación. Es posible suponer que estos fueron los objetivos de la institución desde su creación a principios del siglo XIX.

30. Este catálogo de manuscritos se divide en tres tomos y contiene, además, dos índices temáticos y uno onomástico. Tal como se indica en la descripción de este fondo provista por el Archivo General de la Nación, el mismo abarca alrededor de siete mil cuatrocientos (7.400) documentos ordenados cronológicamente y fechados entre 1492 y 1882. Actualmente, el fondo se encuentra organizado en "ochocientos ochenta y cinco (885) legajos y libros manuscritos encuadernados. Cada legajo está integrado por piezas numeradas, ordenadas cronológicamente". Información provista por el personal del Archivo General de la Nación (s/f, s/e).

31. La obra, de 185 páginas, se encuentra dividida en los siguientes capítulos: "Introduction”; “ L'occupation actuelle"; "Les voyages de découvertes"; "Les premières occupations"; "Conclusion”; “ Documents"; "Traduction espagnole des state papers relatifs à l'incident de 1770-1771".

32. "Pour les personnes qui liraeint ce travail dans le tirage à part, il convient d'en préciser le véritable caractère. C'était, en principe, une simple introduction explicative, analogue à toutes celles qui précèdent les documents inédits dont la publication forme la matière habituelle des Anales de la Biblioteca Nacional de Buenos Aires. Quand il nous arrivera, dans les pages suivantes, de faire allusion ou un référence précise, avec indication de la page ou du numéro d'ordre, aux 'Documents sur les iles Malouines', il s'agira, sauf indication contrarire, des pièces contenues dans le tome VI des Anales. Ce recueil, destiné, comme l'indique son titre, a la publicación con introducciones y notas, de documentos relativos al Río de la Plata, n'est officiel qu'au point de vue de la subvention que lui alloue le gouvernement argentin. Pour tout ce qui touche aux choix des matériaux, dont le gouvernement n'a jamais eu ni demandé de connaissances préalables, liberté entière est laissé au directeur de Anales ...” (Groussac 1910, p. 7). La traducción es nuestra.

33. Omitida por completo en el texto impreso.

34. La presente traducción ha pretendido ser fiel al manuscrito original en francés. Sin embargo, con la intención de contribuir a una mejor comprensión del texto, los signos de puntuación han sido modificados en los casos en donde resultó necesario.

35. Podría tratarse de la adormidera marina. En la traducción del Viaje alrededor del mundo se mantiene esta palabra en francés, con una nota al pie en la que se aclara que "el gladiolo o espadaña es una planta acuática de la familia de las Irídeas" (Bougainville 2005, p. 105). Por su parte, Antoine-Joseph Pernety describe estas plantas, a las que también otorga el nombre de glajeux, en las páginas 426 a 428 de su diario de a bordo (Pernety 1769). 
36. Tanto en el manuscrito como en el capítulo IV del Viaje alrededor del mundo (1771) esta especie es llamada gradeau, que en el tomo tercero del diccionario de Trévoux es descripto como un tipo de pejerrey (Berthelin 1762, p. 298).

37. Se ha traducido glajeux por adormidera marina.

38. Bougainville refiere al encuentro de la Étoile y a la entrega de la bandera blanca realizada en junio de 1766 en el capítulo VIII de la primera edición del Viaje alrededor del mundo (1771). Al relatar la experiencia del cruce por el estrecho, señala: "Esa mañana los patagones - que durante toda la noche habían mantenido sus fogatas encendidas en el interior de la bahía de Posesiónelevaron una bandera blanca desde una cumbre, a lo cual respondimos virando la de los navíos. Sin duda, estos patagones eran aquellos que la Étoile había divisado en el mes de junio de 1766 en la bahía de Boucault y a los cuales les había dejado esa bandera como signo de amistad". Las apreciaciones de Bougainville respecto de la amistad entablada con esta población bien podrían leerse en clave política, pues el navegante afirma: "El esmero con que la han conservado revela que son hombres apacibles y fieles a su palabra o, al menos, los muestra agradecidos por el regalo que se les ha hecho" (Bougainville 2005, p. 167).

39. Se refiere aquí a las boleadoras.

40. El término en francés es "rassade" y es definido como "perla de vidrio o de esmalte utilizada para la fabricación de collares o brazaletes de pacotilla con los cuales se comerciaba con los indígenas" por el Centre National de Ressources Textuelles et Lexicales (véase http://www.cnrtl.fr/ definition/rassade).

\section{ABSTRACTS}

The present article examines the seven recto and verso in folio manuscripts that constitute the " Observations générales sur les Iles Malouines" (General Observations of the Malouine Islands), signed by Louis-Antoine de Bougainville upon returning the Malouine Islands to the Spanish Crown in April 1767. In them, the French navigator not only describes the winds, tides and climate of the region but also assesses the usefulness of the resources available in the islands as well as their geostrategic position in relation to the interoceanic passage provided by the Strait of Magellan and its inhabitants. Unlike his Voyage autour du monde (1771), the document emphasizes the way in which the French captain judges France should deal with the indigenous populations of the Magellan-Fuegian coast. It is also a source of interest in light of the transformations regarding overseas competition in the mid-Eighteenth century. Finally, its current location in the Archivo General de la Nación (Argentina) invites us to reflect on the political impact of an early experience of colonization in the contemporary world. The manuscript, which has been translated for the first time into Spanish in the present article, will be analyzed in light of these coordinates.

Este artículo examina los siete folios manuscritos en recto y verso que constituyen las “ Observations générales sur les Iles Malouines" (Observaciones generales sobre las Islas Malvinas), firmados por Louis-Antoine de Bougainville en abril de 1767, cuando Francia debió entregar las Islas Malvinas a la Corona española. En este documento el navegante francés no solo describe los vientos, las mareas y el clima de la región sino que evalúa la utilidad de los recursos disponibles en las islas así como su posición geoestratégica en relación con el pasaje interoceánico provisto por el Estrecho de Magallanes y sus habitantes. En contraste con su exitoso Viaje alrededor del 
mundo (1771), el manuscrito evidencia el vínculo que el capitán francés considera debe establecerse con las poblaciones indígenas de la costa magallánico-fueguina. Asimismo, constituye una fuente de interés a la luz de las transformaciones en la competencia ultramarina ocurridas en la segunda mitad del siglo XVIII. Por último, su ubicación actual en el Archivo General de la Nación invita a reflexionar sobre las derivas políticas de una experiencia de colonización temprana en el mundo contemporáneo. Es a partir de las variables mencionadas que se aborda la fuente, traducida aquí por primera vez al español.

\section{INDEX}

Keywords: Malouine Islands, Louis-Antoine de Bougainville, South America, Overseas Expansion, 18th Century

Palabras claves: Islas Malvinas, Louis-Antoine de Bougainville, América meridional, expansión ultramarina, siglo XVIII

\section{AUTHOR}

\section{CAROLINA MARTÍNEZ}

Universidad de Buenos Aires, Universidad Nacional de San Martín y Consejo Nacional de Investigaciones Científicas y Técnicas, Argentina.

Correo electrónico: cmartinez79@gmail.com 